\title{
The Bcl-2 repertoire of mesothelioma spheroids underlies acquired apoptotic multicellular resistance
}

\author{
D Barbone $e^{\star, 1,2}$, JA Ryan ${ }^{3}$, N Kolhatkar ${ }^{1,4}$, AD Chacko², DM Jablons ${ }^{4}$, DJ Sugarbaker ${ }^{5}$, R Bueno ${ }^{5}$, AG Letai ${ }^{3}$, LM Coussens ${ }^{4}$, \\ DA Fennell ${ }^{2}$ and VC Broaddus ${ }^{1}$
}

Three-dimensional (3D) cultures are a valuable platform to study acquired multicellular apoptotic resistance of cancer. We used spheroids of cell lines and actual tumor to study resistance to the proteasome inhibitor bortezomib in mesothelioma, a highly chemoresistant tumor. Spheroids from mesothelioma cell lines acquired resistance to bortezomib by failing to upregulate Noxa, a pro-apoptotic sensitizer BH3-only protein that acts by displacing Bim, a pro-apoptotic Bax/Bak-activator protein. Surprisingly, despite their resistance, spheroids also upregulated Bim and thereby acquired sensitivity to ABT-737, an inhibitor of antiapoptotic Bcl-2 molecules. Analysis using BH3 profiling confirmed that spheroids acquired a dependence on anti-apoptotic Bcl-2 proteins and were 'primed for death'. We then studied spheroids grown from actual mesothelioma. ABT-737 was active in spheroids grown from those tumors $(5 / 7, \sim 70 \%)$ with elevated levels of Bim. Using immunocytochemistry of tissue microarrays of 48 mesotheliomas, we found that most $(33,69 \%)$ expressed elevated Bim. In conclusion, mesothelioma cells in 3D alter the expression of $\mathrm{Bcl}-2$ molecules, thereby acquiring both apoptotic resistance and sensitivity to $\mathrm{Bcl}-2$ blockade. Mesothelioma tumors ex vivo also show sensitivity to $\mathrm{Bcl}-2$ blockade that may depend on Bim, which is frequently elevated in mesothelioma. Therefore, mesothelioma, a highly resistant tumor, may have an intrinsic sensitivity to Bcl-2 blockade that can be exploited therapeutically.

Cell Death and Disease (2011) 2, e174; doi:10.1038/cddis.2011.58; published online 23 June 2011

Subject Category: Cancer

Resistance to apoptosis may underlie the chemoresistance of tumors. ${ }^{1,2}$ Apoptotic resistance and chemoresistance, however, may not be fully reflected in two-dimensional (2D) cell cultures (monolayers). Indeed, when cancer cells are grown as three-dimensional (3D) spheroids, they acquire multicellular resistance that mimics the chemoresistance observed in vivo and can effectively recapitulate some of the complexity of solid tumors. ${ }^{3-5}$

Understanding multicellular resistance may provide key insights into effective therapies for recalcitrant solid tumors such as human malignant mesothelioma, ${ }^{6}$ which usually presents at a late stage as a thick tumor mass. ${ }^{7}$ At this time, few effective therapeutic options are available for mesothelioma patients and survival remains poor. Our group ${ }^{8}$ and others ${ }^{9}$ have found that mesothelioma spheroids acquire multicellular resistance to a variety of treatments. ${ }^{8,9} \mathrm{We}$ decided to focus on resistance to bortezomib (PS-341, Velcade), an agent that has shown promise in pre-clinical studies of mesothelioma ${ }^{10,11}$ and is now being evaluated in clinical trials. Although it is not yet known whether mesothelioma will exhibit resistance to bortezomib, bortezomib resistance, while rare in hematologic cancers, ${ }^{12}$ has been a common problem in solid tumors. ${ }^{13}$
Bortezomib, a proteasome inhibitor, is thought to induce apoptosis via the alteration of expression of $\mathrm{Bcl}-2$ proteins. ${ }^{14}$ Thus, resistance to bortezomib may also manifest itself in changes in the balance of the pro- and anti-apoptotic Bcl-2 molecules. If so, new experimental approaches, such as Bcl-2 homology domain 3 ( $\mathrm{BH} 3$ )-profiling, may be used to uncover the anti-apoptotic barriers mediating resistance. With $\mathrm{BH} 3-$ profiling, the cellular dependence on anti-apoptotic proteins can be decoded based on mitochondrial sensitivity to a panel of $\mathrm{BH} 3$ peptides. ${ }^{15}$ In addition, using mechanistic approaches such as these, it has been seen that anti-apoptotic resistance mechanisms may coexist with a high level of pro-apoptotic potential, a situation termed 'primed for death'. Tumors identified as 'primed for death' may respond to inhibition of the anti-apoptotic defenses with small molecules such as $\mathrm{ABT}-737$, an inhibitor of $\mathrm{Bcl}-2 / \mathrm{X}_{\mathrm{L}} / \mathrm{w}$. Probing of the antiapoptotic strategies of 3D spheroids may reveal vulnerabilities that can be sought in tumors as well.

Here, we have investigated the multicellular resistance and the apoptotic priming that develops in mesothelioma cells grown in 3D spheroids. By using Bcl-2 inhibitors and $\mathrm{BH} 3-$ profiling, we have probed the anti-apoptotic defenses of multicellular spheroids and also of human mesothelioma

\footnotetext{
${ }^{1}$ Lung Biology Center, SFGH, UCSF, San Francisco, CA, USA; ${ }^{2}$ Centre for Cancer Research and Cell Biology, Queen's University, Belfast, Ireland, UK; ${ }^{3}$ Department of Medical Oncology, Dana-Farber Cancer Institute, Boston, MA, USA; ${ }^{4}$ Helen Diller Family Comprehensive Cancer Center, UCSF, San Francisco, CA, USA and ${ }^{5}$ Division of Thoracic Surgery, Brigham and Women's Hospital, Harvard Medical School, Boston, MA, USA

${ }^{*}$ Corresponding author: D Barbone, Lung Biology Center, SFGH, UCSF, 1001 Potrero Avenue, Box 0841, San Francisco, CA 94110, USA. Tel: + 1415 206 6656; Fax: +1 415206 4123; E-mail: dario.barbone@ucsf.edu

Keywords: mitochondria; 3D; chemotherapy; BH3-profiling; bortezomib

Abbreviations: TFS, tumor fragment spheroid; 2D, two-dimensional; 3D, three-dimensional; EPP, extrapleural pneumonectomy; TMA, tissue microarray; $\mathrm{R} 8,8$ arginine-repeat peptide; $\mathrm{BH} 3, \mathrm{Bcl}-2$ homology domain 3
}

Received 21.1.11; revised 19.4.11; accepted 04.5.11; Edited by A Verkhratsky 
grown as tumor fragment spheroids (TFS). This study presents for the first time key insights into the apoptotic repertoire of $3 \mathrm{D}$ spheroids and proposes ways to detect the pro-apoptotic potential within mesothelioma and to exploit it therapeutically.

\section{Results}

Mesothelioma cells acquire resistance to bortezomib when grown as 3D spheroids. We first studied two mesothelioma cell lines, M28 and REN, previously reported to be sensitive to bortezomib-induced apoptosis ${ }^{10}$ and known to form spheroids. ${ }^{8}$ Monolayers and spheroids were treated with increasing doses of bortezomib (1-100 nM) for $48 \mathrm{~h}$. Monolayers displayed an $\mathrm{IC} 50^{(48 \mathrm{~h})}$ of approximately $18 \mathrm{nM}$ (M28) and $9 \mathrm{nM}$ (REN), whereas spheroids exhibited resistance, with an approximate $\mathrm{IC} 50^{(48 \mathrm{~h})}$ of $100 \mathrm{nM}$ (M28 and REN) (Figure 1a).

a
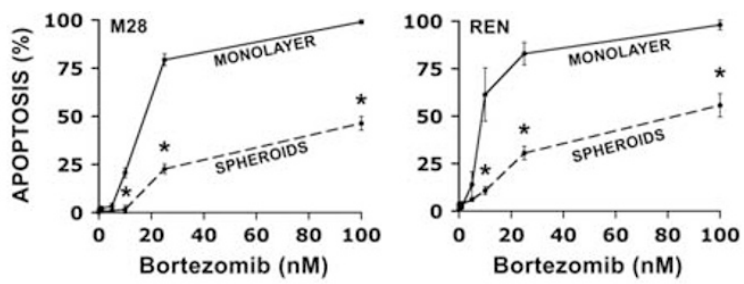

b

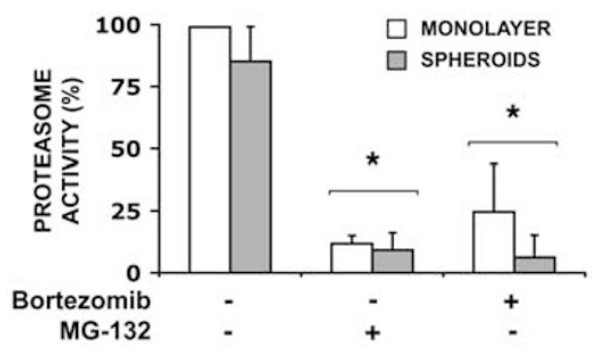

C

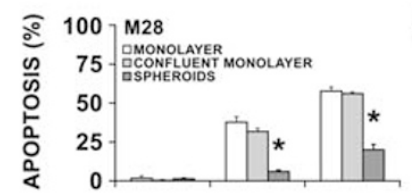

Bortezomib (nM) - $\quad 25 \quad 100$

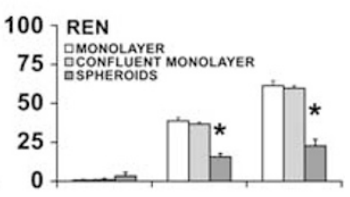

Figure 1 Spheroids grown from mesothelioma cell lines acquire multicellular resistance to bortezomib. (a) M28 and REN monolayers and spheroids were treated with bortezomib $1,5,10,25$ or $100 \mathrm{nM}$ for $48 \mathrm{~h}$. Apoptosis was measured in Hoechst-stained cells; cells with signs of nuclear condensation were considered apoptotic. Spheroids grown from both cell lines acquired a marked multicellular resistance to bortezomib even at the highest concentrations. ( ${ }^{\star} P<0.05$ spheroids compared with monolayers, $n=3$ ). (b) REN monolayers and spheroids were treated with bortezomib $(100 \mathrm{nM})$ or MG-132 $(10 \mu \mathrm{M})$, a potent proteasome inhibitor, for $4 \mathrm{~h}$ before cells were lysed and analyzed for proteasomal activity. Monolayers and spheroids showed similar proteasomal activity at baseline and were both equally inhibited by bortezomib or MG-132 after $4 \mathrm{~h}$. ( ${ }^{*} P<0.05$ compared with untreated control, $n=3$ ). (c) M28 and REN monolayers at standard confluence $(70 \%)$, completely confluent monolayers (obtained by plating twice the number of cells to achieve at least $100 \%$ confluence) and spheroids were treated with bortezomib ( 25 or $100 \mathrm{nM}$ ). Completely confluent monolayers showed an apoptotic response comparable to monolayers and did not acquire multicellular resistance. ( ${ }^{\star} P<0.05$ spheroids compared with monolayers and confluent monolayers, $n=3$ )
Resistance was not due to differences of proteasome activity at baseline or after bortezomib. We found that the proteasomal chymotryptic activity of monolayers and spheroids of REN cells was equal at baseline and equally inhibited following exposure to bortezomib or to another proteasome inhibitor, MG-132, for $4 \mathrm{~h}$ (Figure 1b).

Resistance was not a function of high cell density, as has been proposed. ${ }^{16}$ We found that completely confluent monolayers did not acquire resistance to bortezomib (Figure 1c), but were as responsive to bortezomib as the subconfluent monolayers.

In spheroids, pro-apoptotic Noxa is not upregulated by bortezomib whereas Bim is high. The proteasome recycles $>80 \%$ of the total protein content of cells ${ }^{17}$ and thereby mediates the activity of key cellular functions such as apoptosis. Bortezomib-induced apoptosis has been attributed to the accumulation of the pro-apoptotic BH3only protein Bim and the induction of other pro-apoptotic sensitizers such as Noxa. ${ }^{14,18-20}$ We asked whether bortezomib might alter these apoptotic triggers differently in spheroids and, if so, whether such differences might underlie spheroids' acquired multicellular resistance.

Using immunoblotting, we analyzed the expression of key $\mathrm{Bcl}-2$ proteins in monolayers and spheroids before and after treatment with bortezomib (Figure 2). In monolayers exposed to bortezomib, Noxa was strongly upregulated. In spheroids exposed to bortezomib, however, Noxa failed to increase.

In addition, spheroids upregulated Bim expression at baseline and following bortezomib (Figure 2). Intriguingly, spheroids, despite their increased apoptotic resistance, expressed more pro-apoptotic Bim than did monolayers. Because Noxa functions indirectly by displacing Bim from anti-apoptotic $\mathrm{Mcl}-1$, we asked whether addition of Noxa to the spheroids could restore apoptotic sensitivity.

A Noxa peptide reduces multicellular resistance acquired by spheroids. To confirm that Noxa contributed to the apoptosis induced by bortezomib in the monolayers, we reduced Noxa expression by siRNA. Silencing successfully reduced bortezomib-induced Noxa upregulation, without alteration of other $\mathrm{Bcl}-2$ molecules, Mcl-1 or Bim (Figure 3a). The reduction in Noxa significantly reduced apoptosis in monolayers following bortezomib, suggesting an important role for Noxa in mediating bortezomib-induced apoptosis (Figure 3a). We then attempted to restore Noxa in spheroids using a Noxa ${ }^{\mathrm{BH} 3}$ peptide bound to 8 arginine residues (R8-Noxa ${ }^{\mathrm{BH} 3}$ ), a modification that aids diffusion of the peptide across cell membranes. ${ }^{21,22}$ Although an R8 control peptide had no activity, R8-Noxa ${ }^{\mathrm{BH} 3}$ enhanced the apoptotic response of the spheroids, thereby significantly reducing the multicellular resistance of spheroids to bortezomib (Figure 3b). In addition, R8-Noxa ${ }^{\mathrm{BH} 3}$ alone induced apoptosis in REN spheroids. To determine whether R8-Noxa ${ }^{\mathrm{BH} 3}$ peptide had off-target effects, we ablated $\mathrm{Mcl}-1$ by siRNA. Because Noxa activity requires $\mathrm{Mcl}-1$, we would expect $\mathrm{R} 8-\mathrm{Noxa}^{\mathrm{BH} 3}$ to have no activity in the absence of Mcl-1. Without Mcl-1, R8-Noxa ${ }^{\mathrm{BH} 3}$ lost all apoptotic activity indicating that, at 


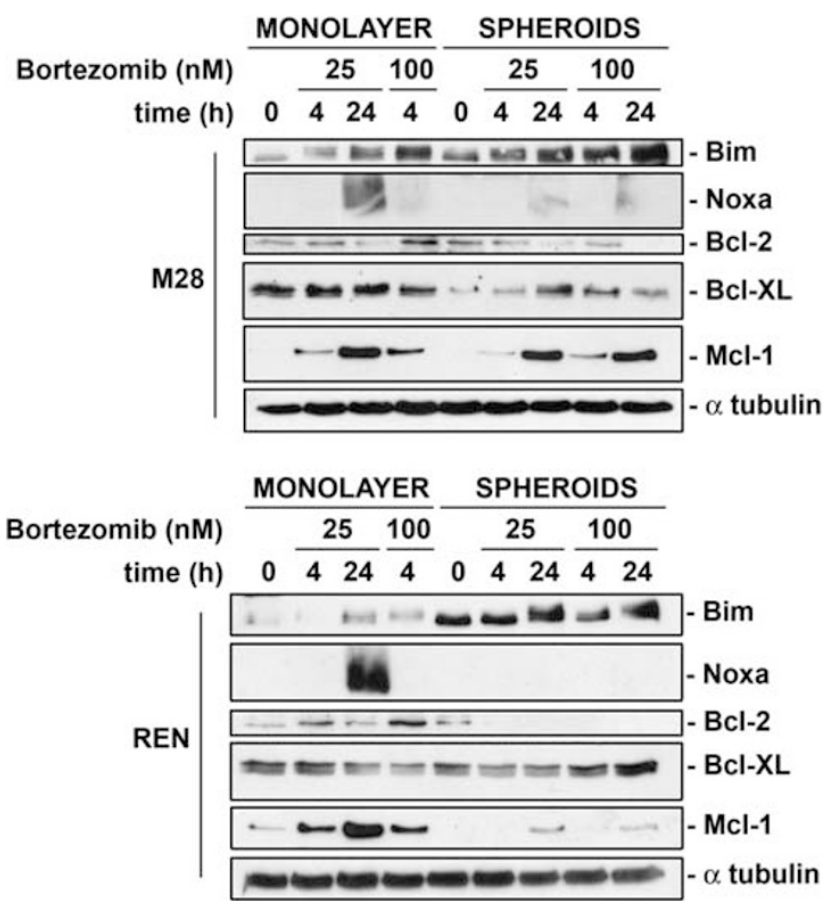

Figure 2 Spheroids fail to upregulate Noxa after bortezomib but have a high expression of Bim. M28 and REN monolayers and spheroids were treated with bortezomib ( 25 or $100 \mathrm{nM}$ ) for 4 or $24 \mathrm{~h}$. Whole cell lysates $(50 \mu \mathrm{g})$ were resolved on SDS-PAGE and immunoblotted for a panel of pro-/anti-apoptotic Bcl-2 proteins. Both M28 and REN monolayers upregulated Noxa after bortezomib ( $25 \mathrm{nM}$ ) at $24 \mathrm{~h}$. (Owing to the high degree of apoptosis, monolayers treated with $100 \mathrm{nM}$ bortezomib at $24 \mathrm{~h}$ were not collected.) Spheroids, however, failed to upregulate Noxa, even after bortezomib $100 \mathrm{nM}$ at $24 \mathrm{~h}$. Interestingly, at baseline and during exposure to bortezomib, spheroids expressed more Bim protein than monolayers. (Representative of three experiments)

least in these cells at the concentrations used, Noxa peptide activity was specifically targeted to Mcl-1 (Supplementary Figure 1).

The activity of the Noxa peptide suggested that the lack of Noxa upregulation in spheroids contributed to the multicellular resistance to bortezomib. Nevertheless, Noxa, as a BH3-only sensitizer, depends on the presence of a pro-apoptotic Bax/Bak-activator such as Bim. The high expression of Bim in the spheroids suggested that the spheroids were primed for apoptotic death and thus vulnerable to other approaches designed to release Bim.

ABT-737 reduces multicellular resistance of spheroids. We asked whether ABT-737, a small molecule that inhibits $\mathrm{Bcl}-2 / \mathrm{X}_{\mathrm{L}} / \mathrm{w}$, would be effective in spheroids by unmasking the pro-apoptotic potential revealed by the R8-Noxa ${ }^{\mathrm{BH} 3}$ peptide. Indeed ABT-737 $(1 \mu \mathrm{M})$ increased the apoptotic response to bortezomib of spheroids as well as of monolayers and reversed the multicellular resistance of spheroids (Figure 4). Moreover, ABT-737 alone induced apoptosis of both M28 and REN spheroids, confirming that spheroids are 'primed for death' ${ }^{15}$ and dependent on their anti-apoptotic defenses for survival. To confirm the role of Bim in the activity of ABT-737, we reduced Bim expression a

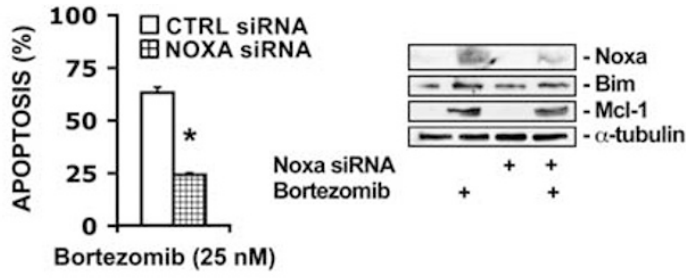

b

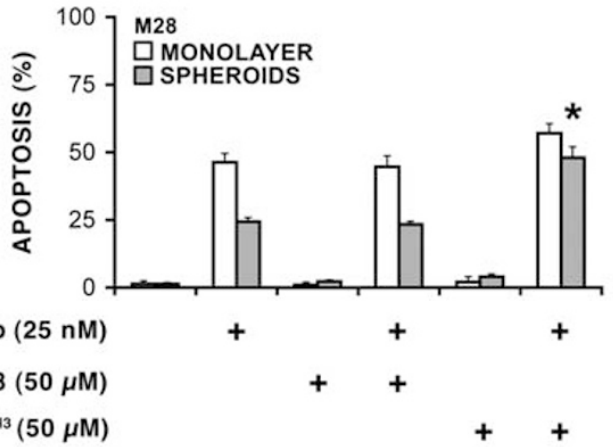

R8-Noxa ${ }^{\mathrm{BH} 3}(50 \mu \mathrm{M})$

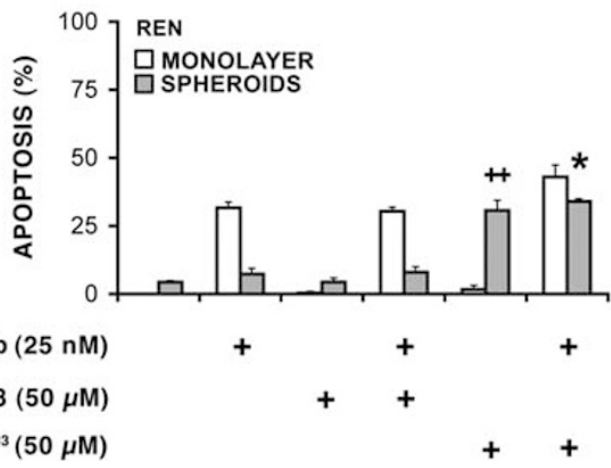

R8-Noxa ${ }^{\mathrm{BH} 3}(50 \mu \mathrm{M})$

Figure 3 A Noxa peptide sensitizes spheroids to bortezomib-induced apoptosis. (a) Noxa was silenced in REN cells and, $24 \mathrm{~h}$ later, cells were plated as monolayers and treated with bortezomib $(25 \mathrm{nM})$. After $4 \mathrm{~h}$, cells were collected and lysed to verify the efficacy of Noxa siRNA (see immunoblot). No changes in other $\mathrm{Bcl}-2$ proteins, Mcl-1 and Bim, were detected upon Noxa silencing, with or without bortezomib. After $24 \mathrm{~h}$, Hoechst-stained cells were counted for the presence of apoptosis. Noxa siRNA significantly reduced the apoptosis induced by bortezomib. ( ${ }^{*} P<0.05, n=3$ ). (b) M28 and REN monolayers and spheroids were treated with bortezomib $(25 \mathrm{nM})$, a cell-permeable R8-Noxa ${ }^{\mathrm{BH} 3}$ peptide $(50 \mu \mathrm{M})$ or a control R8 peptide $(50 \mu \mathrm{M})$, either alone or in combination, for $24 \mathrm{~h}$. R8-Noxa ${ }^{\mathrm{BH} 3}$, but not the R8 peptide, eliminated the acquired multicellular resistance of spheroids to bortezomib without affecting monolayers. Interestingly, REN spheroids, but not $\mathrm{M} 28$, were sensitive to R8-Noxa ${ }^{\mathrm{BH} 3}$ alone. $\left({ }^{*} P<0.05\right.$ compared with untreated and R8 control; ${ }^{+}+P<0.05$ spheroids versus monolayers, $n=3$ )

using siRNA. Knockdown of Bim abolished the ability of ABT-737 by itself to induce apoptosis in spheroids and significantly reduced its ability to enhance bortezomibinduced apoptosis (Figure 5a).

Unlike $\mathrm{Bcl}-2 / \mathrm{X}_{\mathrm{L}} / \mathrm{w}, \mathrm{Mcl}-1$ is not inhibited by $\mathrm{ABT}-737$ and is known to mediate resistance to $A B T-737 .{ }^{23,24}$ We ablated Mcl-1 using siRNA to determine its contribution to resistance in spheroids. Ablation of $\mathrm{Mcl}-1$ increased the apoptotic responses to $A B T-737$ and to bortezomib (Figure 5b). In fact, inhibition of both $\mathrm{Bcl}-2 / \mathrm{X}_{\mathrm{L}} / \mathrm{w}$ (by $\mathrm{ABT}-737$ ) and $\mathrm{Mcl}-1$ (by siRNA) increased the apoptosis in M28 and REN spheroids, to 100 and $65 \%$ of total cells, respectively, even in the absence of bortezomib. 


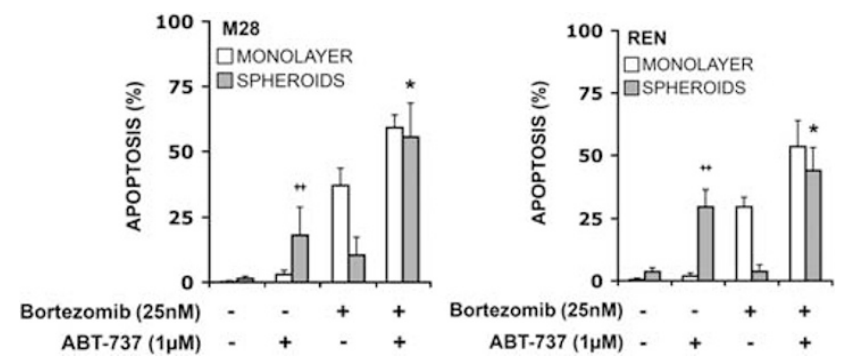

Figure 4 ABT-737 eliminates multicellular resistance to bortezomib. M28 and REN monolayers and spheroids were treated with bortezomib $(25 \mathrm{nM})$ and ABT-737 $(1 \mu \mathrm{M})$, either alone or in combination, for $24 \mathrm{~h}$. ABT-737 eliminated the acquired multicellular resistance of spheroids to bortezomib. Interestingly, when given alone, ABT-737 was able to induce apoptosis in spheroids but not in monolayers. $\left({ }^{\star} P<0.05\right.$ compared with bortezomib alone; ${ }^{++} P<0.05$ spheroids versus monolayers, $n=3$ )

ABT-737 has been shown in some settings to alter levels of $\mathrm{Bcl}-2$ proteins, ${ }^{25-27}$ including $\mathrm{Mcl}-1$. To address this issue, we grew REN cells as monolayers and spheroids and exposed them to $\mathrm{ABT}-737$ alone or to $\mathrm{ABT}-737$ together with bortezomib for $6 \mathrm{~h}$. During that time, selected to avoid the changes induced by apoptosis, we found no significant change in the levels of two $\mathrm{Bcl}-2$ proteins, $\mathrm{Mcl}-1$ and $\mathrm{Bim}$ (Supplementary Figure 2).

To determine whether ABT-737 or bortezomib acts on the benign counterpart of mesothelioma, we studied normal mesothelial cells obtained from benign human ascites. Because benign mesothelial cells in vivo exist as single cell monolayer and in vitro do not form spheroids as readily as do malignant cells, we studied them as monolayers. Normal mesothelial cells did not undergo apoptosis following bortezomib, ABT-737 alone or bortezomib plus ABT-737 (Supplementary Figure 3A). The normal cells also did not express Bim, even following bortezomib treatment for $6 \mathrm{~h}$ (Supplementary Figure 3B).

Spheroids are 'primed for death'. Mesothelioma cells in 3D spheroids thus appeared to acquire apoptotic resistance along with an underlying sensitivity to apoptosis. We used BH3-profiling to confirm these findings in four cell lines (two epithelioid lines, M28 and REN and two sarcomatous lines, SARC and VAMT). For these studies, cells from monolayers and spheroids were disaggregated identically to single cells for flow cytometry and probed with a panel of $\mathrm{BH} 3$ peptides or small molecules such as ABT-737 for the loss of mitochondrial potential indicative of apoptosis. ${ }^{15}$

Cells derived from monolayers and spheroids were equally sensitive to the $\mathrm{Bim} \mathrm{BH} 3$ peptide, confirming an equal ability to activate the apoptotic program (Figure 6). However, compared with cells from monolayers, cells from spheroids were more sensitive to sensitizer BH3-only molecules, Bad and $\mathrm{Hrk}$, targeting $\mathrm{Bcl}-2$ and $\mathrm{Bcl}-\mathrm{X}_{\mathrm{L}}$, respectively. In addition, cells from spheroids were confirmed to be more sensitive to ABT-737, which had no effect on the cells from monolayers.

Because cells from spheroids of the two additional mesothelioma cell lines, VAMT and SARC, were found to be sensitive to pro-apoptotic sensitizers by BH3-profiling, we

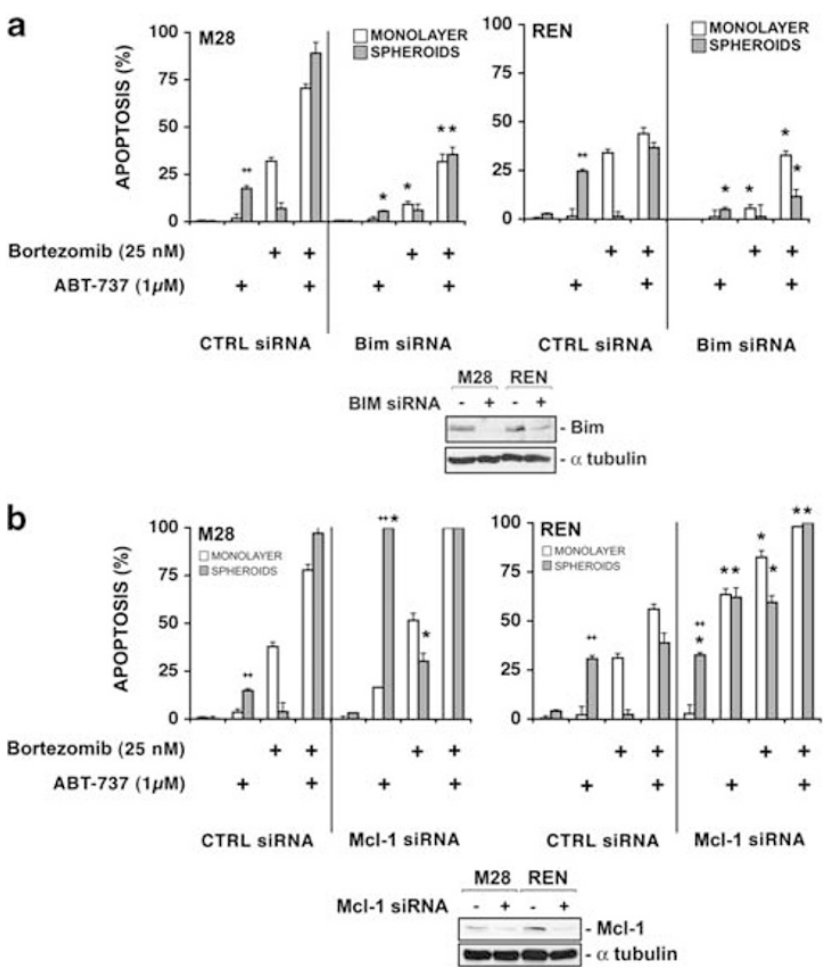

Figure 5 ABT-737 sensitization of spheroids to bortezomib is dependent on Bim and aided by ablation of Mcl-1. (a) Bim was ablated in M28 and REN cells and, $24 \mathrm{~h}$ later, cells were plated to generate monolayers and spheroids, exposed to bortezomib $25 \mathrm{nM}$ and/or ABT-737 $1 \mu \mathrm{M}$ for $24 \mathrm{~h}$ and lysed and probed for Bim at $72 \mathrm{~h}$ after siRNA (see immunoblot insert), the time when cells were counted for the presence of apoptosis. The absence of Bim in spheroids completely abolished the apoptotic effect of ABT-737 when given alone and significantly reduced the effect when given with bortezomib. ( ${ }^{*} P<0.05$ compared with control siRNA, ${ }^{++} P<0.05$ spheroids versus monolayers, $n=3$ ). (b) Mcl-1 was ablated, as performed for Bim above (see immunoblot insert). The absence of Mcl-1 reduced the acquired multicellular resistance of spheroids to bortezomib. The absence of Mcl-1 also increased the apoptotic response to ABT-737 when given alone or in combination with bortezomib. ( ${ }^{\star} P<0.05$ compared with control siRNA, ${ }^{++} P<0.05$ spheroids versus monolayers, $n=3$ )

anticipated that they would also show sensitivity to BH3-only sensitizers when tested in cell culture. Indeed, spheroids of both cell lines were sensitive to ABT-737- and R8-Noxa ${ }^{\mathrm{BH}}$ induced apoptosis, even in the absence of bortezomib (Figure 7a). When spheroids from all four cell lines were compared, the M28 spheroids appeared to have less sensitivity, with no response to $\mathrm{R} 8-\mathrm{Noxa}^{\mathrm{BH} 3}$ given alone (see also Figure $3 b$ ). We then confirmed that the expression levels of Bim increased in each cell line when grown as spheroids. Of interest, the increase in Bim levels as estimated by the ratio of densitometry values was less in M28 (1.9-fold increase) when compared with the more sensitive lines (3.24.5-fold increase) (Figure $7 \mathrm{~b}$ and Supplementary Figure 4)

ABT-737 has activity against human mesothelioma grown as TFS. The sensitivity of multicellular spheroids to $\mathrm{Bcl}-2$ blockade with $\mathrm{ABT}-737$ raised the intriguing possibility that human mesothelioma tumor cells in their 3D environment might also be sensitive. Using a human tumor 


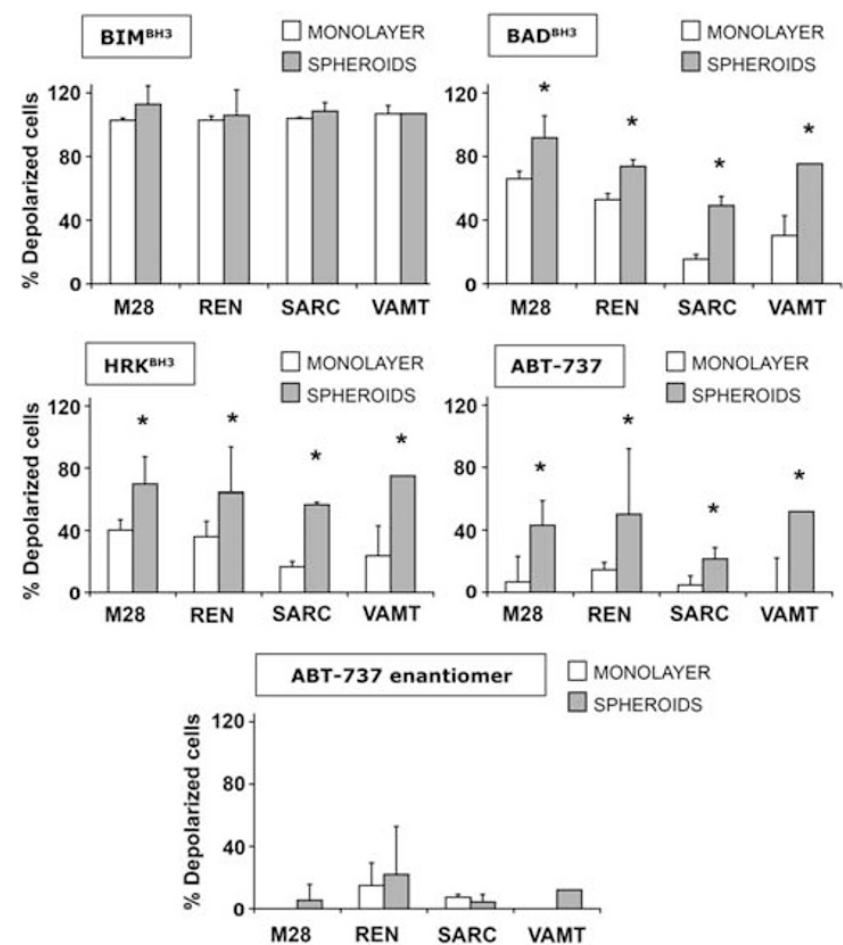

Figure 6 Spheroids are 'primed for death'. BH3-profiling was performed on cells disaggregated from monolayers and spheroids grown from M28, REN, SARC and VAMT cells. The cells were gently permeabilized as described ${ }^{39}$ and exposed to BH3 peptides $(100 \mu \mathrm{M})$ for $90 \mathrm{~min}$ before $\mathrm{JC} 1$ was added for $30 \mathrm{~min}$ and depolarization measured as a percentage of the total. Cells from spheroids and monolayers were equally depolarized by $\mathrm{Bim}^{\mathrm{BH} 3}$, the positive control, confirming a functioning apoptotic apparatus. However, cells disaggregated from spheroids were more sensitive to $\mathrm{Bad}^{\mathrm{BH} 3}$, $\mathrm{Hrk}^{\mathrm{BH} 3}$ and $\mathrm{ABT}-737$ than cells from monolayers, confirming that cells in $3 \mathrm{D}$ acquired apoptotic priming. Cells showed no response to an ABT-737 inactive enantiomer, used as negative control. ( ${ }^{\star} P<0.05$ compared with monolayers, $n=3$ )

fragment model we previously developed for ex vivo studies, ${ }^{5}$ we tested spheroids grown from seven mesothelioma tumors for responsiveness to ABT-737. In tumor fragments from five of the tumors, ABT-737 did sensitize the mesothelioma cells to bortezomib-induced apoptosis (Figures $8 a$ and b). In two cases, there was no response to ABT-737 ( $<5 \%$ apoptosis), either when ABT-737 was given alone or together with bortezomib. We then asked whether the level of Bim expression could explain the different responses to ABT-737 in these tumors. Using immunohistochemistry of a tissue microarray (TMA) comprising the original tumor samples from which the TFS were derived, we found that the responsive tumors showed high Bim expression compared with normal pleura, whereas the unresponsive tumors expressed Bim at low or undetectable levels, comparable to normal pleura (Figure $8 \mathrm{c}$ ). The possibility that Bim could represent a predictive biomarker for ABT-737 activity in mesothelioma prompted us to investigate the frequency of Bim overexpression in mesothelioma tumors. Using immunohistochemistry of 48 mesothelioma samples and 5 normal pleural samples included on a tumor TMA and assessed using an image analysis system, we found that a
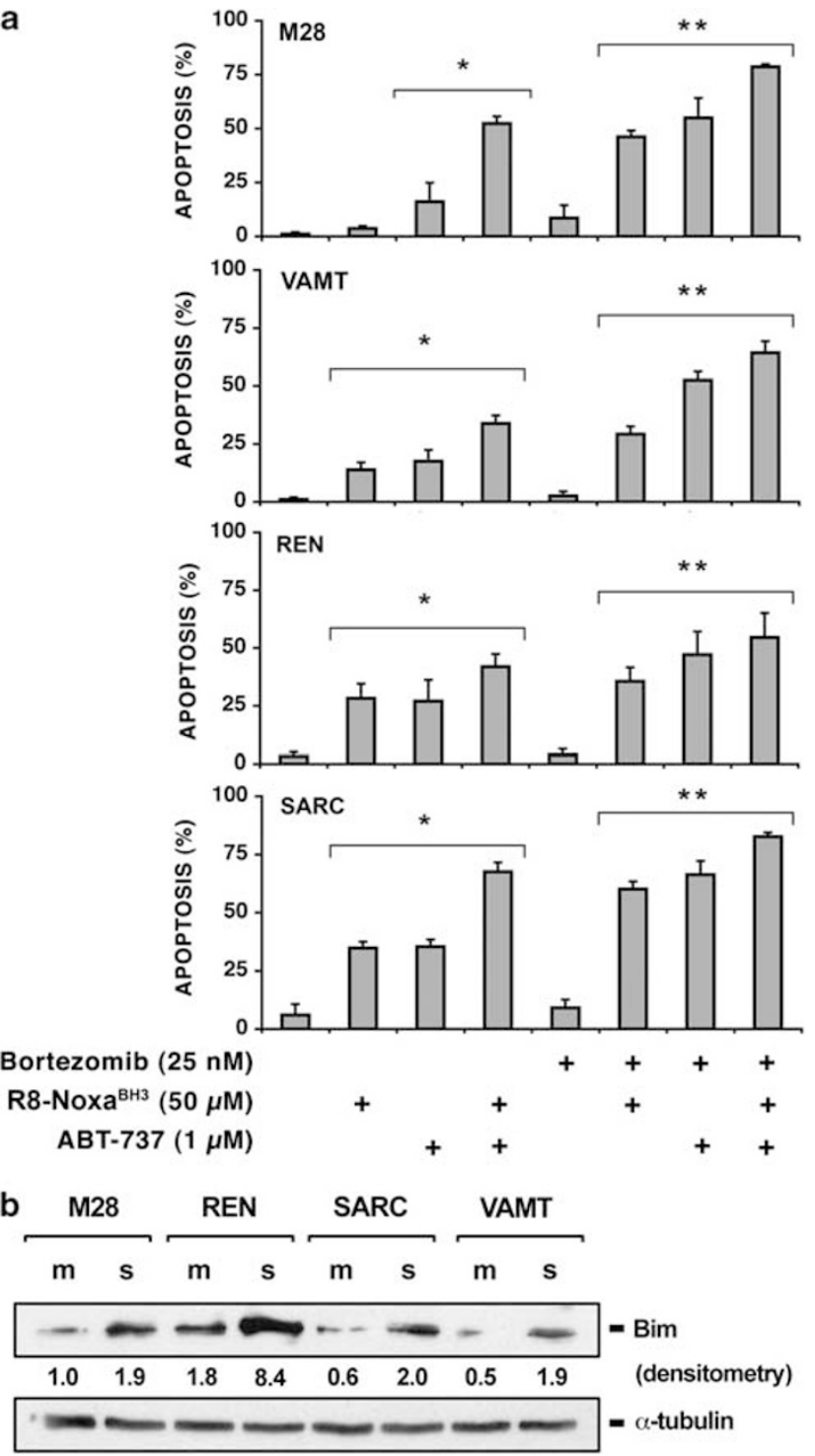

Figure 7 Apoptotic priming of spheroids increases with elevated Bim expression. (a) Spheroids grown from M28, VAMT, REN and SARC cell lines were treated with R8-Noxa ${ }^{\mathrm{BH} 3}(50 \mu \mathrm{M})$, ABT-737 $(1 \mu \mathrm{M})$, bortezomib $(25 \mathrm{nM})$ or their combination for $24 \mathrm{~h}$. Whereas R8-Noxa ${ }^{\mathrm{BH} 3}$ alone failed to induce apoptosis in M28 spheroids, ABT-737 alone induced apoptosis in the spheroids generated from all four cell lines. Nevertheless, when given with bortezomib, either R8-Noxa ${ }^{\mathrm{BH} 3}$ or ABT-737 was effective in increasing apoptosis of spheroids. ( ${ }^{*} P<0.05$ compared with untreated spheroids, ${ }^{* *} P<0.05$ compared with bortezomib alone, $n=3$ ). (b) Immunoblot analysis of Bim expression in M28, REN, SARC and VAMT monolayers and spheroids with densitometry shown for Bim, standardized for $\alpha$-tubulin expression. Immunoblot and densitometry values are representative of three separate experiments. In all four cell lines, spheroids expressed increased Bim levels. Compared with monolayers, spheroids of M28 displayed a 1.9-fold increase in Bim levels whereas spheroids of REN, SARC and VAMT showed a 4.5-, 3.2- and 4.0-fold, increase, respectively

$33(69 \%)$ of mesothelioma tumors expressed Bim at levels higher than in the normal tissues. Elevated Bim expression was found in most tumors of the epithelioid (20 of 22) and mixed subtype (12 out of 21 ) but was uncommon in the sarcomatous subtype (only 1 of 5 ). 
a

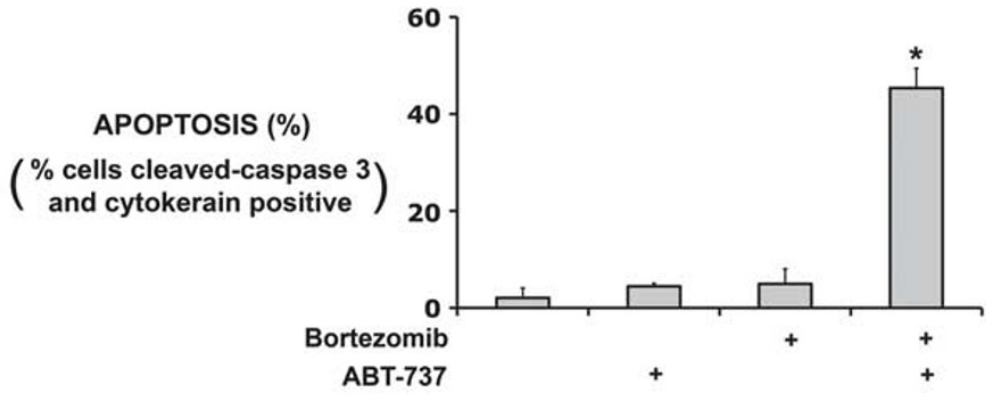

b No treatment

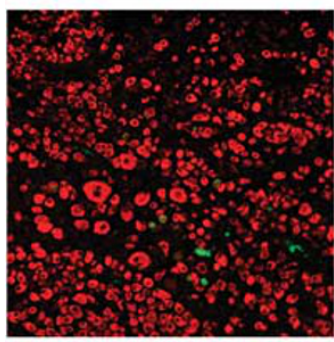

Bortezomib
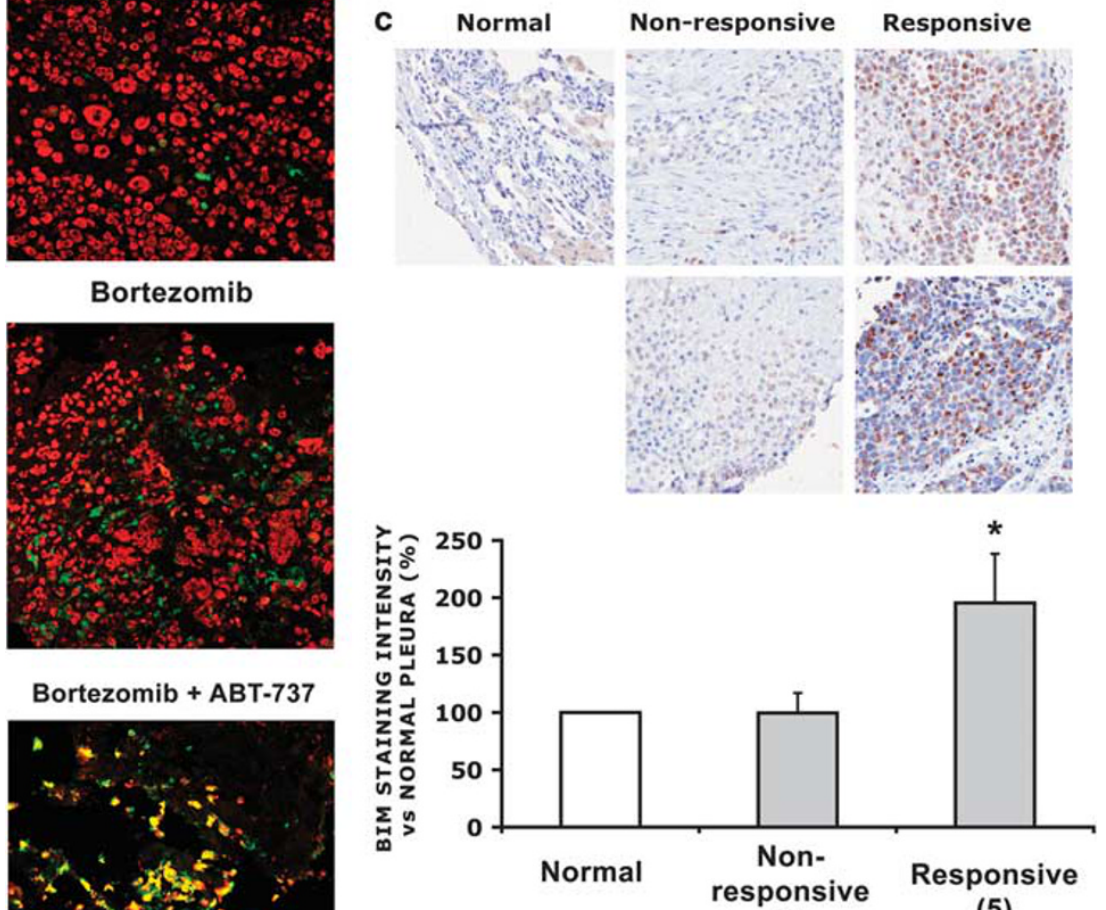

(2)

Bortezomib + ABT-737

(5)

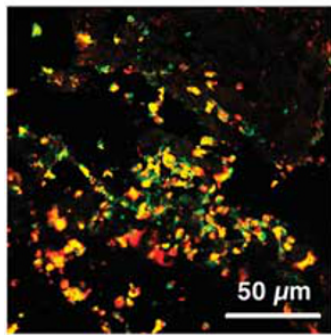

Figure 8 ABT-737 increases activity of bortezomib against mesothelioma cells in spheroids derived from tumors with high expression of Bim. (a) TFS generated from seven tumors were treated with bortezomib $(50 \mathrm{nM})$, ABT-737 $(2.5 \mu \mathrm{M})$ or their combination for $24 \mathrm{~h}$. In the responsive tumors $(n=5)$ (shown), ABT-737 increased apoptosis when given together with bortezomib. In unresponsive tumors $(n=2)$ (not shown), ABT-737 with or without bortezomib had no effect (apoptosis $<5 \%$ ), ( ${ }^{*} P<0.05$ compared with no treatment, bortezomib alone or ABT-737 alone, $n=5$ ). (b) Confocal images representative of the responsive tumor fragment spheroids treated with bortezomib $(50 \mathrm{nM})$ with or without ABT-737 $(2.5 \mu \mathrm{M})$ for $24 \mathrm{~h}$. Pan-cytokeratin (red) was used to identify mesothelioma cells within the spheroids and cleaved caspase-3 (green) to identify apoptosis. The merged color (yellow) identifies apoptotic mesothelioma cells. The mesothelioma cells are resistant to ABT-737 alone (not shown) and to bortezomib alone. The addition of ABT-737 to bortezomib, however, effectively increased apoptosis of the human mesothelioma cells. (c) Using a TMA generated with tissue from the original seven tumors tested for apoptosis along with normal pleural tissue as control, Bim expression was determined by immunohistochemistry and quantified using an imaging analysis system (ScanscopeXT, Aperio). Every sample was represented three times on the slide. Normal pleura and the two tumors not responsive to ABT-737 and bortezomib showed comparable, very low amounts of Bim. Conversely, the responsive tumors showed strong Bim staining. Intensity of staining was expressed as percentage compared with normal pleura. ( ${ }^{*} P<0.05$ compared with normal and non-responsive)

\section{Discussion}

Understanding how cancer cells attain chemoresistance can provide clues for designing new therapeutic strategies. Because cancer cells in 3D cultures acquire a multicellular resistance that resembles the chemoresistance seen in solid tumors in vivo, 3D models may be a useful platform for investigating novel therapeutic approaches. In this study, as in previous studies in our laboratory, we investigated resistance mechanisms using 3D models generated from cell lines that we then tested for relevance in tumor grown ex vivo. ${ }^{8,28} \mathrm{We}$ were particularly interested in applying this approach to 
bortezomib, a therapy that has shown less efficacy in solid tumors than in non-solid tumors such as multiple myeloma, perhaps because of resistance mechanisms seen only in 3D. Although 2D models have been used to elucidate resistance to bortezomib, ${ }^{29}$ here we show for the first time the additional multicellular resistance mechanisms that develop in 3D. Compared with the same cells in $2 \mathrm{D}$, mesothelioma cells in $3 \mathrm{D}$ express a different balance of $\mathrm{Bcl}-2$ pro- and anti-apoptotic molecules and acquire a dual nature: on the one hand, they become resistant to bortezomib; on the other hand, they become dependent on anti-apoptotic Bcl-2 defenses and therefore sensitive if the anti-apoptotic mechanisms are neutralized. In the ex vivo human mesothelioma tumor model, we found that blockade of the Bcl-2 anti-apoptotic molecules enhanced the apoptotic response to bortezomib, at least in tumors with overexpression of the pro-apoptotic BH3-only molecule Bim. The response of the in vitro and ex vivo models to inhibition of anti-apoptotic Bcl-2 members supports a new, clinically relevant approach to this highly chemoresistant tumor.

Mesothelioma cells in 3D acquired a resistance to bortezomib that was initially identified by an inability to upregulate Noxa, the pro-apoptotic BH3-only molecule that interacts with $\mathrm{Mcl}-1$ to release $\mathrm{Bim}^{30}$ In many systems, Noxa has been shown to mediate bortezomib activity, ${ }^{31-33}$ a role we confirmed in the mesothelioma monolayers. In spheroids, the addition of a R8-Noxa ${ }^{\mathrm{BH} 3}$ peptide was able to restore bortezomib-induced apoptosis to the same level as in the monolayers, suggesting that the lack of Noxa upregulation contributed to the bortezomib resistance in 3D. Because Noxa acts indirectly by releasing Bim, we suspected that the effect of Noxa depended on Bim and, as expected, the ablation of Bim decreased the activity of Noxa. However, we were surprised at the high level of Bim in the 3D spheroids, especially given their chemoresistance. It suggested that the Bim was sequestered and held in check by anti-apoptotic buffering and that, despite apoptotic resistance, spheroids would be poised for apoptosis if the Bim could be released. Indeed, the small molecule, ABT737, an inhibitor of $\mathrm{Bcl}-2 / \mathrm{X}_{\mathrm{L}} / \mathrm{w}$, was able to undermine the bortezomib resistance of spheroids and, in some cell lines, to induce apoptosis in spheroids by itself. In fact, when used as single agents in the resistant spheroids, ABT-737 was more effective than bortezomib.

By $\mathrm{BH} 3$-profiling, we confirmed that the cells disaggregated from the spheroids had acquired sensitivity to $A B T-737$ and to peptides that displace Bim from Bcl-2 and $\mathrm{Bcl}-\mathrm{X}_{\mathrm{L}}$. Of interest, the apoptotic priming was acquired as the malignant cells moved to $3 \mathrm{D}$, a feature that has not previously been described. Analogous to what has been proposed for cancer in general, spheroids acquired resistance to apoptosis along with a latent pro-apoptotic potential that could be harnessed therapeutically. ${ }^{34}$

Mcl-1 can confer resistance to ABT-737 as well as to bortezomib, ${ }^{31-33}$ and can be a major resistance factor in 3D spheroids, as we have previously shown in lung cancer. ${ }^{35}$ Interestingly, in our studies in mesothelioma, the presence of $\mathrm{Mcl}-1$ did not prevent the response to ABT-737 although the reduction of $\mathrm{Mcl}-1$ (by $\mathrm{R} 8-\mathrm{Noxa}^{\mathrm{BH} 3}$ or by $\mathrm{Mcl}-1$ siRNA) did increase the response to ABT-737, as has been previously shown. ${ }^{23}$ Thus, Mcl-1 appeared to blunt, but not block, the activity of $A B T-737$ and the combined inactivation of both $\mathrm{Mcl}-1$ and the $\mathrm{Bcl}-2 / \mathrm{X}_{\mathrm{L}} / \mathrm{w}$ was more effective than inhibition of either one alone. Mcl-1 also appeared to have a smaller role when the increase in Bim levels was lower. For example, R8-Noxa ${ }^{\mathrm{BH} 3}$ was less effective than ABT-737 in the cell line with the lowest increase in Bim (M28). Therefore, we speculate that Bim may be preferentially sequestered by $\mathrm{Bcl}-2 / \mathrm{X}_{\mathrm{L}} / \mathrm{w}$, as has been described, ${ }^{36}$ with additional buffering by $\mathrm{Mcl}-1$ as Bim increases. Nonetheless, $\mathrm{Mcl}-1$ represents a potential barrier to the use of ABT-737 clinically. Thus, the effectiveness of ABT-737 in combination with bortezomib or other therapies may be enhanced by agents that reduce Mcl-1.23,25,26

Why Bim increases in the 3D spheroids is not yet known; nonetheless, the finding that Bim increases in mesothelioma cells in 3D represents a unique and potentially important observation. Bim was essential for the response to ABT-737, as demonstrated by the Bim siRNA experiments, and the level of Bim correlated with sensitivity to ABT-737 in the multicellular spheroids and in the tumor fragments. Bim may thus be a useful predictive biomarker for the response of mesothelioma to ABT-737 together with bortezomib. Almost $70 \%$ of mesotheliomas were found to express Bim at levels higher than in normal tissue. Interestingly, Bim overexpression was frequent in the more chemosensitive subtype (epithelioid, 90\%) and uncommon in the more chemoresistant subtype (sarcomatoid, 20\%). Unleashing the pro-apoptotic molecule Bim using small molecule inhibitors such as ABT-737 may enhance the effectiveness of current chemotherapy in this recalcitrant tumor.

TFS were developed to investigate therapeutic approaches in a clinically relevant ex vivo setting. ${ }^{5}$ When tested in TFS, ABT-737 was also effective, but only in spheroids derived from tumors with a high expression of Bim. Thus, by virtue of studies in these complementary 3D models, we have identified a potential therapy, ABT-737, and identified a possible biomarker for predicting response to ABT-737 in this tumor, Bim. Further studies will be necessary to confirm the validity of these predictions. Nonetheless, we think that agents able to upregulate Bim, such as vorinostat, ${ }^{37}$ could be potent adjuncts to current chemotherapies.

There are potential clinical benefits to targeting tumors at the level of their anti-apoptotic defenses. Most targeted therapies have focused on impairing signaling pathways on which cancers depend for survival. ${ }^{38}$ However, the efficacy of these approaches may be impaired by intracellular signaling redundancy, crosstalk, adaptation and differing levels of activating/silencing mutations. Direct inhibitors of anti-apoptotic defenses could bypass the need to inhibit multiple pathways by moving to a distal level at which multiple signals are integrated. Our data suggest that such an approach may be effective in the different mesothelioma subtypes, against a variety of apoptotic therapies, and without injury to normal tissues.

In sum, using 3D culture models, we have shown that multicellular resistance to bortezomib is mediated by alterations in the $\mathrm{Bcl}-2$ repertoire, which provides a druggable target specific to the malignant cells. Inhibition of the anti-apoptotic buffers in association with chemotherapy represents a promising strategy for the treatment of mesothelioma. 


\section{Materials and Methods}

Cell cultures and reagents. The human mesothelioma cell lines M28, REN, VAMT and SARC were cultured in DMEM supplemented with $10 \% \mathrm{FBS}$ and $100 \mathrm{IU} / \mathrm{ml}$ penicillin-streptomycin in a $37^{\circ} \mathrm{C}$ humidified incubator with $5 \% \mathrm{CO}_{2}$ (full DMEM). Primary human mesothelial cells were cultured from ascites fluid from patients without infection or malignancy according to a protocol approved by the UCSF Committee on Human Research. TFS were generated as previously described ${ }^{28}$. Tumor samples were obtained from extrapleural pneumonectomy (EPP) or pleurectomy procedures performed by DJS and RB at Brigham and Women's Hospital in Boston, MA, USA.

R8-Noxa ${ }^{\text {BH3 }}$ (RRRRRRRR-EVECATQLRRFGDKLNFRQKL) and R8 (RRRRRRRR) peptides were from Genscript (Piscataway, NJ, USA). Bortezomib (Velcade) was from Millennium Pharmaceuticals (Cambridge, MA, USA). ABT-737 was generously provided from Abbott Pharmaceuticals (Abbott Park, IL, USA).

\section{Generation and treatment of spheroids}

Multicellular spheroids. Multicellular spheroids were generated in nonadsorbent round-bottomed 96-well plates. The 96-well plates were coated with a 1:24 dilution of polyHEMA (120 mg/ml) (\#P3932, Sigma-Aldrich, St. Louis, MO, USA) in $95 \%$ ethanol and dried at $37^{\circ} \mathrm{C}$ for $48 \mathrm{~h}$. Before use, plates were sterilized by UV light for $30 \mathrm{~min}$. For generation of multicellular spheroids, 10000 cells were added into each well of polyHEMA-coated 96-well plate. The plates were briefly spun for 5 min at 800 r.p.m. and then placed in a $37^{\circ} \mathrm{C}$ humidified incubator with $5 \%$ $\mathrm{CO}_{2}$ for $24 \mathrm{~h}$. For generation of monolayers, 180000 cells were added into each well of six-well plates.

Tumor fragment spheroids. TFS were grown from seven tumor samples obtained from surgical resection performed at the Brigham and Women's Hospital (Boston, MA, USA). A part of the tumor was fixed in 10\% formalin (Fisher Scientific, Fair Lawn, NJ, USA) and embedded in paraffin. For spheroid culture, tumor tissue was diced finely with scalpels to pieces smaller than $1 \mathrm{~mm}$ in diameter that were suspended in medium in $10-\mathrm{cm}$ plates coated with $0.8 \%$ agar (Agar Noble, \#A5431, Sigma-Aldrich) in full DMEM. The volume of overlay media was $15 \mathrm{ml}$, and half the volume of the overlay media was changed twice a week. The agar-coated plates were regularly observed using an inverted phase microscope during the incubation period, up to 4 weeks. Spheroids were collected at different time points, treated as described in figure legends, fixed in $10 \%$ formalin and embedded in paraffin for immunostaining.

Treatment. Before treatment, 18 multicellular spheroids or 20-30 TFS were transferred to each well of a polyHEMA-coated 24-well plate to match the numbers of cells plated as monolayers (180000 cells per well). The spheroids and monolayers were treated with apoptotic agents in full DMEM with or without inhibitors (and the appropriate DMSO vehicle control) for $24 \mathrm{~h}$.

Immunoblotting. After treatment, monolayers and spheroids were lysed in

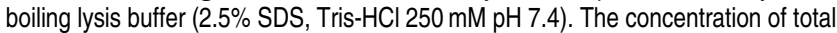
protein was evaluated with a colorimetric assay (DC protein assay from Bio-Rad, Hercules, CA, USA). In all, $50 \mu \mathrm{g}$ of cell lysates were loaded in reducing conditions (0.2 M Tris, pH 6.8, $5 \%$ SDS, 3\% glycerol, $0.01 \%$ bromophenol blue and $200 \mathrm{mM}$ DTT). After separation in SDS-PAGE (5 to $15 \%$ acrylamide) and transfer to PVDF (Immobilon, Millipore, Billerica, MA, USA), membranes were blocked with a proteinfree TBS blocking buffer (Pierce, Rockford, IL, USA) and gently agitated with antibodies diluted in $5 \%$ non-fat dry milk or $5 \%$ BSA, as appropriate, at $4{ }^{\circ} \mathrm{C}$ overnight. Secondary antibodies were from Amersham (Piscataway, NJ, USA). Chemiluminescence was detected with the enhanced SuperSignal West Pico Substrate (Pierce). The antibodies against Bcl-2 (\#2872) and Bcl- $X_{L}(\# 2764)$ were from Cell Signaling Technology (Beverly, MA, USA). The Mcl-1 (sc-819) antibody was from Santa Cruz Biotechnology (Santa Cruz, CA, USA), the Bim antibody (\#559685) was from BD Pharmingen (San Jose, CA, USA), and the Noxa antibody was from Calbiochem (\#OP180, San Diego, CA, USA). The $\alpha$-tubulin antibody (\#T-6074) was from Sigma-Aldrich.

Proteasome activity assay. Proteasome activity in REN spheroids and monolayers was measured using a commercial 20S proteasome activity assay kit (APT280, Millipore Corporation). In brief, spheroids and monolayers were lysed with proteasome activity buffer ( $50 \mathrm{mM}$ HEPES (pH 7.5), $5 \mathrm{mM}$ EDTA, $150 \mathrm{mM} \mathrm{NaCl}$ and $1 \%$ Triton X-100). The lysates were incubated with the fluorogenic substrate LLVY-AMC, a fluorophore 7-amino-4-methylcoumarin (AMC) bound with LLVY peptide, at $37^{\circ} \mathrm{C}$ for $2 \mathrm{~h}$. LLVY is a substrate recognized and cleaved by the $20 \mathrm{~S}$ proteasome. After LLVY chymotryptic cleavage by the $20 \mathrm{~S}$ proteasome, AMC is released and emits fluorescence that can be read by using a $380 \mathrm{~nm}$ excitation and a $460 \mathrm{~nm}$ emission filter in a fluorometer.

RNA interference. Cells $\left(4 \times 10^{6}\right)$ were pelleted and resuspended in $100 \mu \mathrm{l}$ of nucleofection buffer (solution T, Amaxa Biosystems, Cologne, Germany) with $1.5 \mu \mathrm{g}$ of the appropriate siRNA duplex (Ambion, Austin, TX, USA). A non-targeting siRNA sequence was utilized as control in all experiments. This suspension was transferred to a sterile cuvette and nucleofected using program T-20 on a Nucleofector II device (Amaxa Biosystems). After 30-min recovery in complete DMEM medium, the cells were plated and allowed to grow for $24 \mathrm{~h}$. Cells were then trypsinized, counted and plated as monolayers and spheroids for $24 \mathrm{~h}$, and exposed to apoptotic stimuli. The siRNA sequences were: Bim ( $5^{\prime}$-ACUUACAUCAGAAG GUUGCtt-3'), Mcl-1 (5'-CCAGUAUACUUCUUAGAAAtt--3') and Noxa (5'-GAAAU GUGUCAAUAAUUACtt-3'), non-targeting control (5'-GCAACCUUCUGAUGUAA GUtt-3').

BH3 profiling. Experiments were performed at the Dana Farber Cancer Institute (Boston, MA, USA) by JA Ryan and AG Letai as previously published. ${ }^{39}$ Monolayers and spheroids formed from equal numbers of cells were disaggregated in an identical fashion to single cells. The cells were gently permeabilized as described ${ }^{39}$ and exposed to $\mathrm{BH} 3$ peptides $(100 \mu \mathrm{M})$ for 90 min before $\mathrm{JC} 1$ was added for $30 \mathrm{~min}$ and depolarization measured as a percentage of the total.

Hoechst staining for measurement of apoptosis in multicellular spheroids. Monolayers and spheroids were disaggregated by exposure to trypsin for the same period of time, washed with ice-cold PBS, and then fixed with $2.5 \%$ glutaraldehyde (Sigma-Aldrich). The cells were then stained with $8 \mu \mathrm{g} / \mathrm{ml}$ of Hoechst 33342 (Molecular Probes, Invitrogen, Carlsbad, CA, USA) and placed on slides. For each condition, at least 300 cells were counted in triplicate by investigators blinded to the experimental conditions. Cells with distinctive signs of nuclear condensation were considered apoptotic.

Confocal analysis for measurement of apoptosis in TFS. In all, $5 \mu \mathrm{m}$ paraffin sections were deparaffinized with Xylene $(2 \times 5 \mathrm{~min}), 100 \% \mathrm{EtOH}$ ( $2 \times 2 \mathrm{~min}), 95 \% \mathrm{EtOH}(2 \times 2 \mathrm{~min}), 70 \% \mathrm{EtOH}(2 \times 2 \mathrm{~min}), 50 \% \mathrm{EtOH}(1 \times 2 \mathrm{~min})$ and ddH2O $(2 \times 2 \mathrm{~min})$. Endogenous peroxidases were blocked with a solution of $250 \mathrm{ml} \mathrm{MeOH}+5 \mathrm{ml} 30 \% \mathrm{H}_{2} \mathrm{O}_{2}$ for $20 \mathrm{~min}$. Antigens were retrieved in citrate buffer (Citra \#HK087-5K, Biogenex, Fremont, CA, USA) in a microwave oven set to high for 7-8 min. Sections were blocked with a 5\% normal goat serum, 2.5\% BSA in PBS for 30-45 min in humidified chamber at RT. Primary antibodies for cleaved caspase 3 (1:100, \#AB3623, Chemicon, Billerica, MA, USA) and pan-cytokeratin (1:100, Progen, Heidelberg, Germany; clone GP14) were incubated in a humidified chamber at $4{ }^{\circ} \mathrm{C}$ overnight. The secondary antibodies donkey anti-rabbit AlexaFluor 488 (Pierce; \#31821) and anti-guinea pig AlexaFluor 633 (Invitrogen; \#A-21105), both $1: 200$, were incubated for $30-45 \mathrm{~min}$ at RT in a humidified chamber. Slides were washed three times in PBS for 3 min and mounted with Vectashield. In a blinded fashion, the investigators examined images of doubly stained slides. Apoptotic mesothelioma cells were considered cells that had merged red (pancytokeratin) and green (cleaved caspase 3 ) and were expressed as a percentage of the total cells (DAPI-stained nuclei). For each condition, 3-10 spheroids were counted until a total of $300 \mathrm{DAPI}-$ stained cells were visualized.

Bim immunohistochemistry of TMAs. Two TMAs were studied. One included the seven mesothelioma tumors that were studied as TFS for their apoptotic response and two normal pleural samples. The second included 48 mesothelioma tumors and 5 normal pleural samples. All samples were obtained without identifiers from surgeries performed at the Brigham and Women's Hospital and at UCSF Medical Center and were fixed in formalin and assembled in a TMA. Each sample was embedded in triplicate. The histopathology was determined on separate formalin-fixed, hematoxylin- and eosin-stained sections of the tumor. In all, $5 \mu \mathrm{m}$ paraffin sections of the TMA were processed as described for the confocal analysis of apoptosis. Bim antibody $\left(1: 150,4^{\circ} \mathrm{C}\right.$ overnight) was visualized with a HRP/DAB Envision + Kit (Dako, Carpinteria, CA, USA; \#K4010). Intensity of Bim staining was measured by the Positive Pixel Count algorithm on a ScanscopeXT system (Aperio Technologies, Inc., Vista, CA, USA), which determined the average intensity of pixels within the tissue region of interest.

Statistical analysis. Data are expressed as mean \pm 1 S.D. of at least three different experiments. Statistical significance was evaluated by one- or two-way 
analysis of variance, and Tukey's test was performed to detect where the differences lay (GraphPad Prism v 4.0, GraphPad Software, Inc., La Jolla, CA USA). A $P$-value $<0.05$ was considered significant.

\section{Conflict of Interest}

The authors declare no conflict of interest.

Acknowledgements. This work was supported by a TRDRP fellowship to DB (18FT-0120), an Ireland/NCI Consortium grant to VCB, DAF and DB (CDV/3679/07) and a Department of Defense Mesothelioma Program grant to VCB and LMC (PR080717).

1. Johnstone RW, Ruefli AA, Lowe SW. Apoptosis: a link between cancer genetics and chemotherapy. Cell 2002; 108: 153-164.

2. Hanahan D, Weinberg RA. The hallmarks of cancer. Cell 2000; 100: 57-70.

3. Smalley KS, Lioni M, Herlyn M. Life isn't flat: taking cancer biology to the next dimension In Vitro Cell Dev Biol Anim 2006; 42: 242-247.

4. Pampaloni F, Reynaud EG, Stelzer EH. The third dimension bridges the gap between cell culture and live tissue. Nat Rev Mol Cell Biol 2007; 8: 839-845.

5. Kim KU, Wilson SM, Abayasiriwardana KS, Collins R, Fiellbirkeland L, Xu Z et al. A novel in vitro model of human mesothelioma for studying tumor biology and apoptotic resistance. Am J Respir Cell Mol Biol 2005; 33: 541-548.

6. Fennell DA, Gaudino G, O'Byrne KJ, Mutti L, van Meerbeeck J. Advances in the systemic therapy of malignant pleural mesothelioma. Nat Clin Pract Oncol 2008; 5: 136-147.

7. Fennell DA, Rudd RM. Defective core-apoptosis signalling in diffuse malignan pleural mesothelioma: opportunities for effective drug development. Lancet Oncol 2004; 5: 354-362.

8. Barbone D, Yang T, Morgan J, Gaudino G, Broaddus V. Mammalian target of rapamycin contributes to the acquired apoptotic resistance of human mesothelioma multicellular spheroids. J Biol Chem 2008; 283: 13021-13030.

9. Daubriac J, Fleury-Feith J, Kheuang L, Galipon J, Saint-Albin A, Renier A et al. Malignant pleural mesothelioma cells resist anoikis as quiescent pluricellular aggregates. Cell Death Differ 2009; 16: 1146-1155

10. Sartore-Bianchi A, Gasparri F, Galvani A, Nici L, Darnowski JW, Barbone D et al. Bortezomib inhibits nuclear factor-kappaB dependent survival and has potent in vivo activity in mesothelioma. Clin Cancer Res 2007; 13: 5942-5951.

11. Gordon GJ, Mani M, Maulik G, Mukhopadhyay L, Yeap BY, Kindler HL et al. Preclinical studies of the proteasome inhibitor bortezomib in malignant pleural mesothelioma. Cancer Chemother Pharmacol 2008; 61: 549-558.

12. Shah JJ, Orlowski RZ. Proteasome inhibitors in the treatment of multiple myeloma Leukemia 2009; 23: 1964-1979.

13. Scagliotti GV, Germonpre P, Bosquee L, Vansteenkiste J, Gervais R, Planchard D et al. A randomized phase II study of bortezomib and pemetrexed, in combination or alone, in patients with previously treated advanced non-small-cell lung cancer. Lung Cancer 2010; 68: 420-426.

14. Fennell DA, Chacko A, Mutti L. BCL-2 family regulation by the $20 \mathrm{~S}$ proteasome inhibitor bortezomib. Oncogene 2008; 27: 1189-1197.

15. Certo M, Del Gaizo Moore V, Nishino M, Wei G, Korsmeyer S, Armstrong SA et al. Mitochondria primed by death signals determine cellular addiction to antiapoptotic BCL-2 family members. Cancer Cell 2006; 9: 351-365.

16. Butcher DT, Alliston T, Weaver VM. A tense situation: forcing tumour progression. Nat Rev Cancer 2009; 9: 108-122.

17. Dalton WS. The proteasome. Semin Oncol 2004; 31(6 Suppl 16): 3-9; discussion 33

18. Fribley AM, Evenchik B, Zeng Q, Park BK, Guan JY, Zhang H et al. Proteasome inhibitor PS-341 induces apoptosis in cisplatin-resistant squamous cell carcinoma cells by induction of Noxa. J Biol Chem 2006; 281: 31440-31447.
19. Perez-Galan P, Roue G, Villamor N, Montserrat E, Campo E, Colomer D. The proteasome inhibitor bortezomib induces apoptosis in mantle-cell lymphoma through generation of ROS and Noxa activation independent of p53 status. Blood 2006; 107: 257-264.

20. Puthalakath H, O'Reilly LA, Gunn P, Lee L, Kelly PN, Huntington ND et al. ER stress triggers apoptosis by activating BH3-only protein Bim. Cell 2007; 129: 1337-1349.

21. Futaki S. Oligoarginine vectors for intracellular delivery: design and cellular-uptake mechanisms. Biopolymers 2006; 84: 241-249.

22. Kloss A, Henklein P, Siele D, Schmolke M, Apcher S, Kuehn L et al. The cell-penetrating peptide octa-arginine is a potent inhibitor of proteasome activities. Eur J Pharm Biopharm 2009; 72: 219-225.

23. van Delft MF, Wei AH, Mason KD, Vandenberg CJ, Chen L, Czabotar PE et al. The BH3 mimetic ABT-737 targets selective $\mathrm{Bcl}-2$ proteins and efficiently induces apoptosis via Bak/Bax if Mcl-1 is neutralized. Cancer Cell 2006; 10: 389-399.

24. Yecies D, Carlson NE, Deng J, Letai A. Acquired resistance to ABT-737 in lymphoma cells that up-regulate MCL-1 and BFL-1. Blood 2010; 115: 3304-3313.

25. Bhat UG, Pandit B, Gartel AL. ARC synergizes with ABT-737 to induce apoptosis in human cancer cells. Mol Cancer Ther 2010; 9: 1688-1696.

26. Kang MH, Wan Z, Kang YH, Sposto R, Reynolds CP. Mechanism of synergy of N-(4hydroxyphenyl)retinamide and $\mathrm{ABT}-737$ in acute lymphoblastic leukemia cell lines: Mcl-1 inactivation. J Natl Cancer Inst 2008; 100: 580-595.

27. Hauck P, Chao BH, Litz J, Krystal GW. Alterations in the Noxa/Mcl-1 axis determine sensitivity of small cell lung cancer to the BH3 mimetic ABT-737. Mol Cancer Ther 2009; 8: 883-892.

28. Wilson SM, Barbone D, Yang TM, Jablons DM, Bueno R, Sugarbaker DJ et al. mTOR mediates survival signals in malignant mesothelioma grown as tumor fragment spheroids. Am J Respir Cell Mol Biol 2008; 39: 576-583.

29. Zhang L, Littlejohn JE, Cui Y, Cao X, Peddaboina C, Smythe WR. Characterization of bortezomib-adapted I-45 mesothelioma cells. Mol Cancer 2010; 9: 110.

30. Han J, Goldstein LA, Hou W, Rabinowich H. Functional linkage between NOXA and Bim in mitochondrial apoptotic events. J Biol Chem 2007; 282: 16223-16231.

31. Gomez-Bougie P, Wuilleme-Toumi S, Menoret E, Trichet V, Robillard N, Philippe M et al. Noxa up-regulation and $\mathrm{Mcl}-1$ cleavage are associated to apoptosis induction by bortezomib in multiple myeloma. Cancer Res 2007; 67: 5418-5424.

32. Woo HN, Seo YW, Moon AR, Jeong SY, Choi EK, Kim TH. Effects of the BH3-only protein human Noxa on mitochondrial dynamics. FEBS Lett 2009; 583: 2349-2354.

33. Baou M, Kohlhaas SL, Butterworth M, Vogler M, Dinsdale D, Walewska R et al. Role of NOXA and its ubiquitination in proteasome inhibitor-induced apoptosis in chronic lymphocytic leukemia cells. Haematologica 2010; 95: 1510-1518.

34. Lowe SW, Cepero E, Evan G. Intrinsic tumour suppression. Nature 2004; 432: 307-315

35. Yang TM, Barbone D, Fennell DA, Broaddus VC. Bcl-2 family proteins contribute to apoptotic resistance in lung cancer multicellular spheroids. Am J Respir Cell Mol Biol 2009; 41: 14-23.

36. Chen S, Dai Y, Pei XY, Grant S. Bim upregulation by histone deacetylase inhibitors mediates interactions with the $\mathrm{Bcl}-2$ antagonist $\mathrm{ABT}$-737: evidence for distinct roles for Bcl-2, Bcl-xL, and Mcl-1. Mol Cell Biol 2009; 29: 6149-6169.

37. Dai $Y$, Chen S, Venditti CA, Pei XY, Nguyen TK, Dent $P$ et al. Vorinostat synergistically potentiates MK-0457 lethality in chronic myelogenous leukemia cells sensitive and resistant to imatinib mesylate. Blood 2008; 112: 793-804

38. Reinhardt $\mathrm{HC}$, Jiang $\mathrm{H}$, Hemann MT, Yaffe MB. Exploiting synthetic lethal interactions for targeted cancer therapy. Cell Cycle 2009; 8: 3112-3119.

39. Ryan JA, Brunelle JK, Letai A. Heightened mitochondrial priming is the basis for apoptotic hypersensitivity of CD4+ CD8+ thymocytes. Proc Natl Acad Sci USA 2010; 107: 12895-12900.

Cell Death and Disease is an open-access journal published by Nature Publishing Group. This work is licensed under the Creative Commons Attribution-Noncommercial-No Derivative Works 3.0 Unported License. To view a copy of this license, visit http://creativecommons.org/licenses/by-nc-nd/3.0/

Supplementary Information accompanies the paper on Cell Death and Disease website (http://www.nature.com/cddis) 